\title{
Quality Engineering Techniques
}


$\Rightarrow$ Taylor \& Francis

Taylor \& Francis Group

http://taylorandfrancis.com 


\section{Quality Engineering Techniques}

\section{An Innovative and Creative Process Model}

Ramin Rostamkhani

Mahdi Karbasian 
First edition published 2020

by CRC Press

6000 Broken Sound Parkway NW, Suite 300, Boca Raton, FL 33487-2742

and by CRC Press

2 Park Square, Milton Park, Abingdon, Oxon, OX14 4RN

C 2020 Taylor \& Francis Group, LLC

CRC Press is an imprint of Taylor \& Francis Group, LLC

Reasonable efforts have been made to publish reliable data and information, but the author and publisher cannot assume responsibility for the validity of all materials or the consequences of their use. The authors and publishers have attempted to trace the copyright holders of all material reproduced in this publication and apologize to copyright holders if permission to publish in this form has not been obtained. If any copyright material has not been acknowledged please write and let us know so we may rectify in any future reprint.

Except as permitted under U.S. Copyright Law, no part of this book may be reprinted, reproduced, transmitted, or utilized in any form by any electronic, mechanical, or other means, now known or hereafter invented, including photocopying, microfilming, and recording, or in any information storage or retrieval system, without written permission from the publishers.

For permission to photocopy or use material electronically from this work, access www.copyright.com or contact the Copyright Clearance Center, Inc. (CCC), 222 Rosewood Drive, Danvers, MA 01923, 978-750-8400. For works that are not available on CCC please contact mpkbookspermissions@tandf.co.uk

Trademark notice: Product or corporate names may be trademarks or registered trademarks, and are used only for identification and explanation without intent to infringe.

Library of Congress Cataloging-in-Publication Data

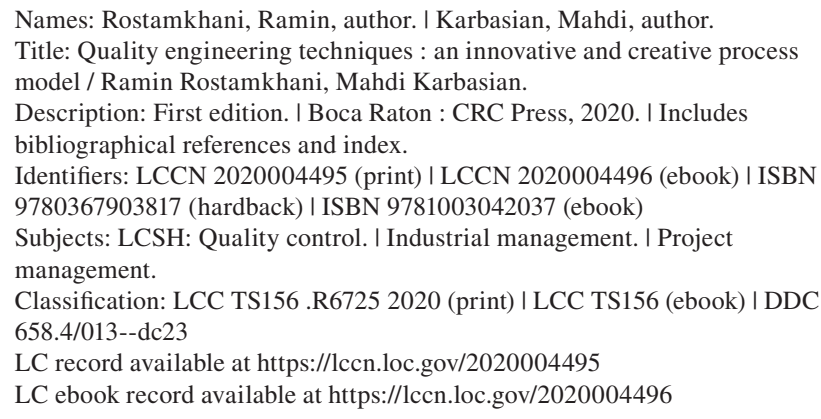

ISBN: 978-0-367-90381-7 (hbk)

ISBN: 978-1-003-04203-7 (ebk)

Typeset in Times

by Deanta Global Publishing Services, Chennai, India 


\section{Contents}

Preface ix

About the Authors. xi

Chapter 1 A Review of the Basic Concepts ........................................................ 1

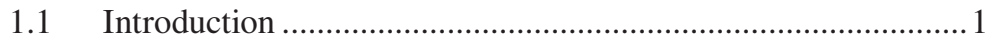

1.2 The History of Research in QET ................................................

1.2.1 The History of Research in Statistical Techniques ......2

1.2.1.1 Descriptive Statistics .......................................2

1.2.1.2 Design and Analysis of Experiments ............5

1.2.1.3 Statistical Hypothesis Tests ............................ 6

1.2.1.4 Process Capability Analysis ..........................

1.2.1.5 Regression Analysis....................................... 8

1.2.1.6 Reliability Analysis ......................................

1.2.1.7 Sampling ……………………................... 11

1.2.1.8 Simulation................................................. 12

1.2.1.9 Statistical Process Control Charts ............... 12

1.2.1.10 Statistical Tolerances .................................... 14

1.2.1.11 Time Series Analysis .................................... 14

1.2.2 The History of Research in Non-Statistical

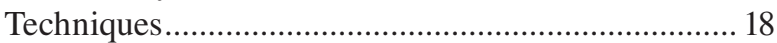

1.3 The History of Research in the Key Concepts of Continuous Improvement ......................................................... 19

1.3.1 The History of Research in Productivity for Industrial Products Manufacturing ..............................20

1.3.2 The History of Research in Sustainability for Industrial Products Manufacturing ..............................21

1.3.3 The History of Research in Added Values for Industrial Products Manufacturing ..............................21

1.4 A Summary of the Research History ……………………........22

1.4.1 Innovation and Creativity in This Research:

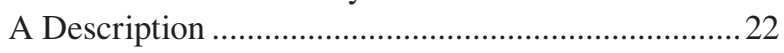

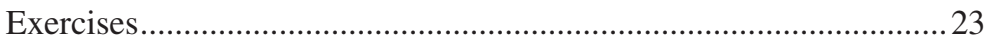

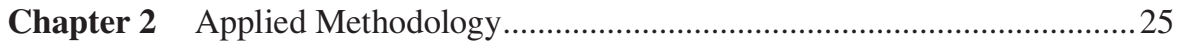

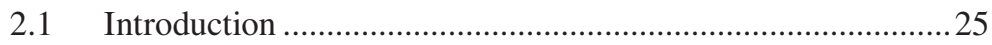

2.2 Research Limitations............................................................25

2.3 Statistical Population of the Research ....................................25

2.4 Data Collection Tools and Methods ……………....................22

2.5 Data Collection Validity …………………………………........27 
2.6 Data Collection Reliability 27

2.7 Information Analysis Method 27

Exercise

Chapter 3 Proposed Model in Triple Organizational Processes 29

3.1 Introduction .29

3.2 Identification and Determination of Three Types of Processes in Industrial Factories .29

3.3 Identification and Determination of the Desired QET in Main Processes

3.3.1 A Numerical Application of QET in the Determined Scope for Main Processes 30

3.4 Identification and Determination of the Desired QET in Leadership Processes 50

3.4.1 Numerical Application of QET in the Determined Scope for Leadership Processes

3.5 Identification and Determination of the Desired QET in Support Processes 56

3.5.1 Numerical Application of QET in the Determined Scope for Support Processes .................56

3.5.1.1 Exponential Distribution Function .............58

3.5.1.2 Ultra Exponential Distribution Function ......59

3.5.1.3 Gamma Distribution Function....................59

3.5.1.4 Weibull Distribution Function .....................59

3.5.1.5 Normal Distribution Function ....................60

3.5.1.6 Log-Normal Distribution Function.............60

Exercises

Chapter 4 Results of Implementing the Model .............................................. 65

4.1 Introduction .65

4.2 Z-MR Control Charts for Describing the Impacts of Different Units on Productivity and Sustainability 65

4.3 Total Score Calculation of Productivity and Sustainability before and after Implementing QET 73

4.4 Demonstration of the Growth in Added Values for Industrial Products Manufacturing 75

4.5 Generalizing the Assessment Results of the Model to Other Organizations 77

4.6 Assessing the Model's Risks and Opportunities in Manufacturing Industries .... 77

4.6.1 Risks and Opportunities Identification ....................... 78

4.6.2 Risks and Opportunities Assessment......................... 78

4.6.3 Responding to Risks and Opportunities ................... 78 
4.7 Impacts of Implementing the Model in Industrial Economics ............................................................... 81

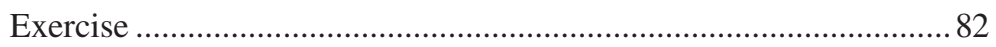

Chapter 5 Quality Engineering Techniques from Past to Future...................... 83

5.1 A Discussion on Comparison of Previous Research with the Proposed Model.......................................................... 83

5.2 Final Results of the Research in Manufacturing Industries ...... 84

5.3 Suggestions for Future Research ......................................8 85

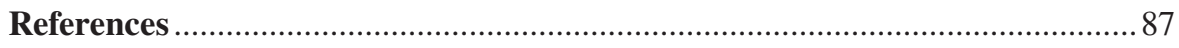

Appendix: Assessment Questionnaire for Generalizing the Proposed Model....... 89

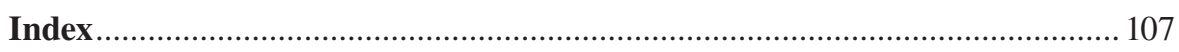


$\Rightarrow$ Taylor \& Francis

Taylor \& Francis Group

http://taylorandfrancis.com 


\section{Preface}

No one can deny the incredible pace of change and progress in today's industrial and complex world. A large amount of information is exchanged and little time is available to deal with it. Many industries and firms of small, medium, or large sizes have a profound desire to increase productivity and sustainability to gain a competitive position in the global market. One of the best tools for achieving this goal is to apply Quality Engineering Techniques (QET). Quality Engineering Techniques can be established through process-oriented models applicable to all traditional processes employed in companies or firms. The authors of this book, having had more than 20 years of intensive work in Quality Management Systems (QMS) and Integrated Management Systems (IMS), have tried to share their applied knowledge and experience on the process-oriented model of quality engineering techniques with experts and managers working at different companies or firms, particularly those in industrial factories. The essential role of employing statistical techniques as the main tool of quality engineering techniques in the growth and development of industries is a well-known fact to the specialists in the field. In applying statistical techniques, the most referenced books in the field are those by Professor Douglas Montgomery from the Arizona State University (ASU) in the United States. In writing this current book, however, we have been inspired by well-known and accomplished professors in industrial engineering in Iran-Professor Rasoul Noorossana in particular-from the Iranian University of Science and Technology. Indeed, the invaluable books and articles he has published could improve knowledge of Quality Engineering Techniques for the first time in Iran. Furthermore, we have benefited from the articles and books published by Professor Arash Shahin from the University of Isfahan; in fact, the important progress and proliferation of quality engineering techniques in Iran have given us enough motivation to write this book. To the above authorities, we have to add the professors and researchers at the Malek Ashtar University of Technology whose great contribution to developing different levels of design and implementation of the process-oriented model are to be appreciated. Also, many experts and managers within this academic organization have cooperated with us in implementing the model presented in this book through applying it to defense sectors. We are indebted to them for their sincere efforts. Special thanks are due to internal and external participants in filling out the questionnaires. We are grateful to our colleagues who played active roles in developing different stages of the model. This model has been applied to a selected industrial factory. The obtained results, however, can be generalized not only to other industries but also to general service sectors. This book introduces, for the first time, an integrated and applicable model for quality engineering techniques and numerical applications for its implementation. It is to be noted that the design of the proposed model is introduced as the main core of the research project while its implementation is indicated in numerical 
application parts. So, the main thrust of our research is to provide answers to the important and essential questions listed below.

- How can we define the main specifications of a productive and sustainable model of QET in industrial organizations?

- How can different levels of the proposed model be configured?

- Which units or individuals are responsible for implementing the intended model of QET?

- How can the impacts of implementing the proposed model in question be assessed?

- Can this model create or increase added values for industrial organizations/ firms?

The proposed model can prove useful to experts and managers who desire to achieve optimum productivity and sustainability through applying quality engineering techniques, whether statistical or non-statistical. The model presented can manage the application of quality engineering techniques in an integrated format for organizational processes. The most creative feature of the presented work is the idea of introducing a process map within an organization, besides exploiting several quality engineering techniques including statistical and non-statistical tools for different levels of the organization. The most innovative dimension of this book is executing the proposed model in an effective format for the defense sectors of Iran that can be generalized to other non-military sectors in each country as well as creating or augmenting added values for the manufacture of industrial products. We firmly believe that our model can be further improved by accommodating constructive experts' views from those authorities working in the manufacturing and general services sectors of organizations/firms. Please, do not hesitate to contact us (see below) and share your highly appreciated comments in regards to the content of the book.

Ramin Rostamkhani and Mahdi Karbasian March 2019 


\section{About the Authors}

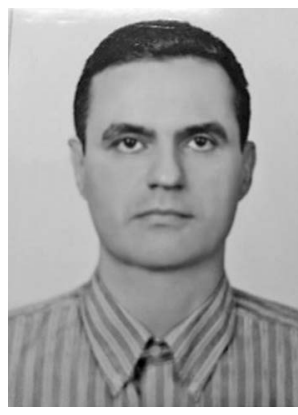

Ramin Rostamkhani has an M.A. in Industrial Engineering. $\mathrm{He}$ earned his master's degree from the Malek Ashtar University of Technology in Tehran, Iran. He has worked in the Defense Industries Organization (DIO) in Iran. He has more than 20 years of experience in QET. Moreover, he has a lot of experience in QMS and IMS. He has written at least four articles in Scopus and ISI journals. He has extensive expertise and experience in the following areas:

- Reliability

- Productivity

- Sustainability

- Quality control

- Applied statistics

- Quality assurance

- Quality engineering

- Statistical and non-statistical techniques

Researchgate https://www.researchgate.net/profile/Ramin_Rostamkhani/publications LinkedIn https://www.linkedin.com/in/ramin-rostamkhani-80446910a/

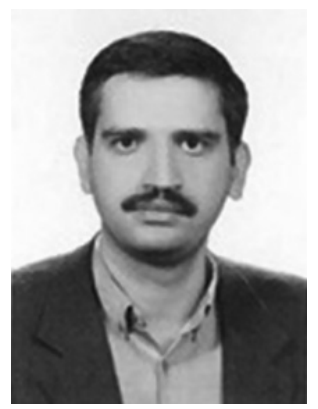

Mahdi Karbasian has a Ph.D. in Industrial Engineering. He earned a Ph.D. from the Tarbiat Modares University of Tehran, Iran. He is an Associate Professor in the Faculty of Industrial Engineering at the Malek Ashtar University of Technology in Esfahan, Iran. He is a manager of many quality projects in the Malek Ashtar University of Technology. He has written many articles in Scopus and ISI journals. He has extensive expertise and experience in the following areas:

- Process safety

- Failure analysis

- Applied statistics

- Reliability analysis

- Quality engineering

Researchgate https://www.researchgate.net/profile/Mahdi_karbasian/publications

LinkedIn https://www.linkedin.com/in/mahdi-karbassian-686ab235/ 
$\Rightarrow$ Taylor \& Francis

Taylor \& Francis Group

http://taylorandfrancis.com 


\section{A Review of the Basic Concepts}

\subsection{INTRODUCTION}

In the present century, quality engineering techniques have turned into applicable and effective tools for attaining advanced design and manufacturing technology as well as mass-production processes. The rationale behind these techniques from the very beginning was to help mass-production lines. It was only later that such methods were developed into useful instruments for other activities in the organization (both for pre-production activities such as product design, and for subsequent activities like after-sales services. Appropriate techniques are developed depending on the type of organization. The evolution path for quality engineering techniques (QET) (passing from low to high quality) has occurred synchronously with development in manufacturing lines. Various techniques have been developed and applied at each stage of the formation of a product (depending on the organization). However, it is important to note that most of the techniques are based on systematic processes, i.e., fewer inputs for converting qualitative outputs into quantitative ones. The result is that these techniques can establish a safe platform for decision making. That is to say, although these techniques can be applied individually, the logical nature is that when they are applied one after another, they act as reinforcements and exhibit double effects. The importance of the functional role of statistical techniques as a main core of QET for robust analysis of the data related to the indices of the strategic issues of quality management systems cannot be easily overlooked. The World Organization for Standardization, through one of its subcommittees, has shed light on identifying statistical techniques. This informative manual appears in two editions, in 1999 and 2003, where it is officially designated as ISO10017 which applies to all standards in the ISO9000 family, especially to those in ISO9001. This standard is a very useful tool in the identification of statistical techniques in the deployment, maintenance, improvement, and development of quality management systems. Statistical techniques as a mathematical tool in quality engineering play a crucial role in measuring, describing, analyzing, interpreting, and modeling system changes even with limited data. Statistical analyses in data can help us understand the extent and causes of changes. Hence, statistical techniques can prove beneficial in exploiting available data to help with decision making and to continuously improve the quality of products and processes, eventually improving customer satisfaction which is the most important goal of the organization. These techniques can be applied to an extensive range of activities such as market research, design, development, production, verification, and servicing. 


\subsection{THE HISTORY OF RESEARCH IN QET}

Statistical control charts were employed by Shewhart for the first time in 1920 . However, the relevant sciences flourished in the years between the two world wars. Later years witnessed the use of statistical quality control techniques in manufacturing military equipment. In the years after the war, i.e., in the 1950s and 1960s, the experiments, designs, and analysis techniques were also used. This time not only the military industries, but also the major automobile companies and their part makers turned to these sciences. Major companies like General Electric, General Motors, and Motorola provided a new era for testing these statistical techniques and even resorted to other engineering techniques that did not require strong statistical bases (non-statistical techniques) (Rezaei, 2001). In the field of statistical and non-statistical techniques, a great number of studies have been carried out whose implementation records can be seen in numerous references. It seems that a perfect application grounds for designing and implementing of QET can be realized in the defense sector where widespread and consistent processes are observable at three levels of processes: namely, main, leadership, and support procedures. One particular study discusses the advantage of applying statistical and non-statistical techniques related to quality engineering in the form of an integrated model for creating productivity and sustainability in the main domains of industrial engineering associated with manufacturing factories. (Karimi Gavareshki et al., 2018). The popular statistical techniques based on ISO10017 and non-statistical techniques are presented in Figure 1.1.

Figure 1.2 presents another categorization for QET.

\subsubsection{The History of Research in Statistical Techniques}

The family of statistical techniques that can help an organization achieve its objectives is as follows: (ISO10017:2003)
A. Descriptive statistics
B. Design and analysis of experiments
C. Statistical hypothesis tests
D. Process capability analysis
E. Regression analysis
F. Reliability analysis
G. Sampling
H. Simulation
I. Statistical process control charts
J. Statistical tolerances
K. Time series analysis

\subsubsection{Descriptive Statistics}

Descriptive statistics refers to the methods employed to summarize quantitative data in such a way as to define the characteristics of data distribution. The characteristics of data mostly taken into consideration are the central value of data (e.g., averages); 


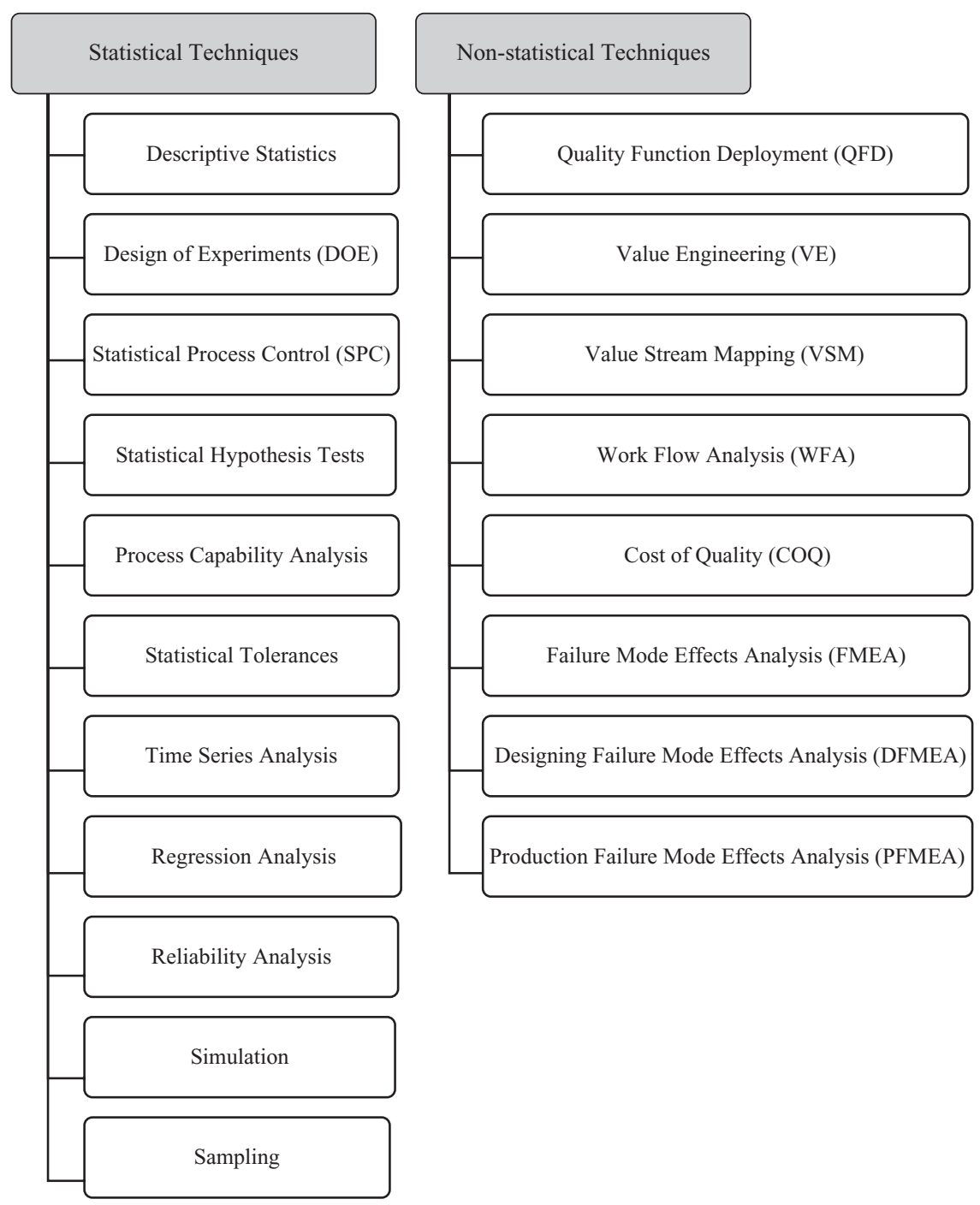

FIGURE 1.1 QET; statistical and non-statistical techniques.

and the dispersion of data (e.g., domains or standard deviations). Another feature of interest is the shape of the distribution of data (e.g., symmetries). The information obtained from descriptive statistics can often be easily and effectively influenced by resorting to various types of graphical methods including histogram charts, Pareto graphs, dispersion charts, causation charts or trend graphs. These graphical methods are useful since they are capable of discovering unusual aspects in the data that are vague in quantitative analyses. These methods are widely used in data analysis when the researcher decides to discover or verify the relationship among variables and intend to estimate the parameters used to describe these relationships. 


\section{References}

Abbasi, M., Rostamkhani, R., (2014), Reliability Application of Industrial Manufacturing Networks in Outsourcing, Journal of Engineering and Quality Management, Volume 3, No. 4, Pages 247-259.

Andrade, A.R., Johnson, T., Stow, J., (2018), Application of Waves Trapping Statistical Technique to Estimate an Extreme Value in Train Aerodynamics, Journal of Wind Engineering and Industrial Aerodynamics, Volume 175, Pages 419-427. https://doi. org/10.1016/j.jweia.2018.02.009

Barua, A., Deb, P.K., Maheshwari, R., Tekade, R.K., (2018), Chapter 10-Statistical Techniques in Pharmaceutical Product Development, In R.K. Tekade (ed.), Dosage Form Design Parameters, Volume 2, Pages 339-362, National Institute of Pharmaceutical Education and Research (NIPER), Ahmedabad, India. https://doi. org/10.1016/B978-0-12-814421-3.00010-5

Bounazef, D., Chabani, C., Idir, A., Bounazef, M., (2014), Management Analysis of Industrial Production Losses by the Design of Experiments, Statistical Process Control, and Capability Indices, Journal of Business and Management, Volume 2, No. 1, Pages 65-72. https://doi.org/10.4236/ojbm.2014.21009

Cristovao, R.O., Pinto, V.M.S., Goncalvez, A., Martins, R.J.E., Loureiro, J.M., Boaventura, R.A.R., (2018), Fish Canning Industry Wastewater Variability Assessment using Multivariate Statistical Methods, Process Safety and Environmental Protection, Volume 102, Pages 263-276. https://doi.org/10.1016/j.psep.2016.03.016

Domingues, P., Sampaio, P., Arezes, P.M., (2016), Integrated Management Systems Assessment: A Maturity Model Proposal, Journal of Cleaner Production, Volume 124, No. 15, Pages 164-174. https://doi.org/10.1016/j.jclepro.2016.02.103

Espinosa-Garza, G., Loera-Hernandez, I., Antonyan, N., (2017), Increase of Productivity through the Study of Work Activities in the Construction Sector, Manufacturing Engineering Society International Conference, 28-30 June, Vigo (Pontevedra)Spain, Pages 1003-1010. https://doi.org/10.1016/j.promfg.2017.09.100

Federico, E., (2016), Research in Economics and Industrial Organization, Journal of Research in Economics, Volume 70, No. 4, Pages 511-517. https://doi.org/10.1016/j. rie.2016.10.002

Fisher, C., (2014), New Techniques in Project Management, American Journal of Industrial and Business Management, Volume 4, No. 12, Pages 739-750. https://doi.org/ 10.4236/ ajibm.2014.412080

Karbasian, M., Rostamkhani, R., (2017), Application of Design of Experiments Technique in Quality Management System for Assessing Various Factors Affecting Processes Performance of Defense Industries Organization, Sharif Journal of Science and Technology, Volume 33.1, No. 1.1, Pages 95-102. https://doi.org/10.24200/J65.2017.5579

Karbasian, M., Rostamkhani, R., (2019), Achieving Productive Reliability through Applying Statistical Distribution Functions, International Journal of Quality and Reliability Management. https://doi.org/10.1108/IJQRM-11-2018-0298

Karimi Gavareshki, M.H., Abbasi, M., Karbasian, M., Rostamkhani, R., (2018), Application of Quality Engineering Techniques in the Main Domains of Industrial Engineering, Journal of Achievements in Materials \& Manufacturing Engineering, Volume 1, No. 90, Pages 22-40. https://doi.org/10.5604/01.3001.0012.7972

Karimi Gavareshki, M.H., Abbasi, M., Karbasian, M., Rostamkhani, R., (2019), Presenting a Productive and Sustainable Model of Integrated Management System for Achieving an 
Added Value in Organisational Processes, International Journal of Productivity and Quality Management. https://doi.org/10.1504/IJPQM.2019.10023794

Karimi Gavareshki, M.H., Abbasi, M., Rostamkhani, R., (2017), Application of QFD and VE and Lean Approach for Control Tests in a Product Design, Archives of Materials Science and Engineering, Volume 84, No. 2, Pages 65-78. https://doi.org/ 10.5604/01.3001.0010.0980

Karimi Gavareshki, M.H., Sharifi Zamani, M., Rostamkhani, R., (2014), Identification and Determination of Effective Application of Statistical Prioritize Techniques in Quality Management System in Defense Industries Organization, Iranian Electric Industry Journal of Quality and Productivity, Volume 2, No. 4, Pages 18-29.

Lim, A.H.S., Antony, J., (2016), Statistical Process Control Readiness in the Food Industry: Development of a Self-Assessment Tool, Trends in Food Science and Technology, Volume 58, Pages 133-139.

Lin, S.W., Lee, M., Huang, Y.C., Den, W., (2015), Identifying Water Recycling Strategy using Multivariate Statistical Analysis for High-Tech Industries in Taiwan, Resources Conservation and Recycling, Volume 94, Pages 35-42.

Memon, A.J., Shaikh, M.M., (2016), Confidence Bounds for Energy Conservation in Electric Motors: An Economical Solution using Statistical Techniques, Energy, Volume 109, Pages 592-601. https://doi.org/10.1016/j.energy.2016.05.014

Montgomery, D., (1996a), Statistical Quality Control (Eighth Edition), translated to Farsi by Noorossana, R., Iran University of Science and Technology, Tehran, Iran.

Montgomery, D., (1996b), Design and Analysis of Experiments (First Edition), translated to Farsi by Noorossana, R., Iran University of Science and Technology, Tehran, Iran.

Nelson, W., (2004), Accelerated Testing: Statistical Models, Test Plans and Data Analyses, John Wiley \& Sons, Hoboken, New Jersey, USA.

Olawumi, T.O., Chan, D.W.M., (2018), A Scientometric Review of Global Research on Sustainability and Sustainable Development, Journal of Cleaner Production, Volume 183, Pages 231-250. https://doi.org/10.1016/j.jclepro.2018.02.162

Plag, I., (2006), Encyclopedia of Language \& Linguistics (Second Edition), University of Siegen, Siegen, Germany, Pages 121-128.

Porter, A., (2004), Accelerated Testing and Validation, Elsevier, Burlington, MA, USA, Page 01803.

Rajnoha, R., Sujova, A., Dobrovic, J., (2012), Management and Economics of Business Processes Added Value, Procedia, Social and behavioral Sciences, Volume 62, Pages 1292-1296. https://doi.org/10.1016/j.sbspro.2012.09.221

Rezaei, K., (2001), Using of the Quality Engineering Techniques in the Framework of Quality Management Systems, Second International Quality Management Conference, CQM02 - 002, 22-25 July, Tehran-Iran.

Rezazadeh, S., Jahani, A., Makhdoum, M., Meigooni, H.G., (2017), Evaluation of the Strategic Factors of the Management of Protected Areas using SWOT Analysis, Journal of Ecology, Volume 7, No. 1, Pages 55-68. https://doi.org/10.4236/oje.2017.71005

Salomone, R., (2008), Integrated Management Systems: Experiences in Italian Organizations, Journal of Cleaner Production, Volume 16, No. 16, Pages 1786-1806. https://doi. org/10.1016/j.jclepro.2007.12.003

Sima, H., Jana, P., Panghal, D., (2019), Feasibility of Using Simulation Technique for Line Balancing in Apparel Industry, Procedia Manufacturing, Volume 30, Pages 300-307. https://doi.org/10.1016/j.promfg.2019.02.043

Tulcidas, A., Nascimento, S., Santos, B., Alvarez, C., Pawlowski, S., Rocha, F., (2019), Statistical Methodology for Scale-up of an Anti-solvent Crystallization Process in the Pharmaceutical Industry, Separation and Purification Technology, Volume 213, Pages 56-62. https://doi.org/10.1016/j.seppur.2018.12.019

Zhou, X., (2016), Mechanism Design Theory: The Development in Economics and Management, Journal of Business and Management, Volume 4, No. 2, Pages 345-348. https://doi.org/10.4236/ojbm.2016.42036 